\title{
Development of Method to Improve the Efficiency of Drop Penetration in Soybean Plants Dossier
}

\section{Priscila Paula Ribeiro*}

State University of Ponta Grossa, Department of Soil Science and Agricultural Engineering/Sector of Agricultural Science and Technology, Brazil

*Corresponding Author: Priscila Paula Ribeiro, State University of Ponta Grossa, Department of Soil Science and Agricultural Engineering/Sector of Agricultural Science and Technology, Brazil.

Received: June 19, 2019; Published: July 02, 2019

DOI: $10.31080 /$ ASAG.2019.03.0553

\begin{abstract}
The present work aims to evaluate the effectiveness of the fungicide application technique using dispositive to open the canopy of plants for the control of the Asian soybean rust cultivar NS 6209 in comparison with the conventional technology. The experiment was conducted during the 2015/2016 crop, in a randomized complete block in a $2 \times 2$ factorial scheme, using two volumes of fungicide

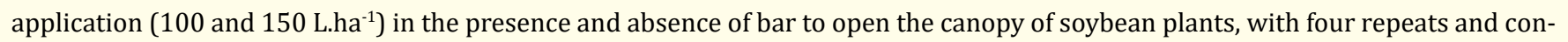
trol treatment. AUDPC (Area under the disease progress curve), severity, thousand grain mass and productivity were evaluated. The results showed that the control of Asian rust in the soybean crop evaluated by the area under the disease progress curve (AUDPC) and severity was more efficient when the fungicide volume of $150 \mathrm{~L}^{\mathrm{h}} \mathrm{ha}^{-1}$ was applied in isolation way with the use of the auxiliary bar, in the lower and upper thirds and, in an associated way, in the middle third of the plants. In the crop yield evaluated by the thousand grain mass ( $\mathrm{g}$ ) and productivity (kg.ha-1), the best results were obtained with the volume of $150{\mathrm{~L} . h a^{-1}}^{-1}$ associated to the use of the auxiliary bar.
\end{abstract}

Keywords: Asian Soybean Rust; Fungicide Volume; Method of Application

\section{Introduction}

The fungus Phakopsora pachyrhizi, the causative agent of "Asian soybean rust" (ASR), is currently the main pathogen of soybean crop, causing significant losses of productivity when its control is not efficient. Applications of contact or systemic fungicides should be carried out uniformly and well distributed in plant tissues, as well as at the time most susceptible to the onset of the pathogen.

\section{Materials and Methods}

This work was carried out at Capão da Onça School Farm, belonging to State University of Ponta Grossa, Ponta Grossa city, Parana State, Brazil.

The experimental design was randomized blocks in a $2 \times 2$ factorial scheme, with two application volumes of 100 and 150 L.ha-1 fungicides and two application procedures (with and without canopy opening of the soybean plants by means of a bar auxiliary) and control, totaling 5 treatments with four repeats.
The auxiliary bar, made of PVC tube with 1 meter in length and $25 \mathrm{~mm}$ in diameter, fixed by metallic structures with adjustments of distance in horizontal and vertical in relation to the bar of the sprayer. In the space of operation of the auxiliary bar were arranged in the bar of the sprayer four tips model XR 11002 spaced $0.50 \mathrm{~m}$ apart.

The soybean cultivar used was NS 6209, seeded on 10/12/2015 with $0.45 \mathrm{~m}$ line spacing, 14 plants. $\mathrm{m}^{-1}$ density and 200 kg.ha-1 fertilization of the commercial formulation of NPK $00-20-20$. The control of Asian soybean rust was carried out with fungicide based on Piraclostrobin and Fluxapiroxade, in the dose of $150 \mathrm{~g}$ of i.a.ha ${ }^{-1,}$ being carried out three applications.

ASR severity assessments were performed at 15 day intervals starting from 5th February 2016 (seven days after each application), totaling three evaluations. For this, 8 leaflets of the lower, middle and upper part were observed, and scores related to the percentage of area damaged by the disease using a diagrammatic scale proposed by Godoy., et al. [1]. 
With the severity data, the area under the disease progress curve (AUDPC), proposed by Campbell and Madden [2], was calculated using the AUDPC program [3].

Thousand grain mass (g) and productivity (kg.ha-1) were also determined based on a sample of 20 plants harvested per parcel, and the values corrected to $13 \%$ water content.

The results obtained were submitted to analysis of variance and the averages of the treatments compared through the Dunnett test and the Tukey test at $5 \%$ probability of error, using the statistical package ASSISTAT Version 7.7 beta [4].

\section{Results and Discussion}

Area Under the Disease Progress Curve - AUDPC

The data showed that the main treatments in relation to the control were statistically different, at $1 \%$ level. Thus, through the Dunnett's test, the averages of AUDPC values were compared considering the lower, middle and upper thirds of the plants, where there was a significant difference in the AUDPC values calculated between the treatments and the control in three thirds, with $5 \%$ of significance.

Analyzing Table 1, it can be seen that the treatment 150 L.ha $^{-1}$ presented lower averages of AUDPC for the three thirds, indicating a greater efficiency in the control of disease spread. On the other hand, the application method revealed that the canopy opening bar showed better results than the experiment with its absence, providing greater contact of the whole plant with the product (in three thirds).

\begin{tabular}{|l|lll|}
\hline $\begin{array}{c}\text { Volume of } \\
\text { Application }\end{array}$ & Lower Third & Middle Third & Upper Third \\
\hline 100 L.ha $^{-1}$ & $2.664,84 \mathrm{a}$ & $1.267,54 \mathrm{a}$ & $344,77 \mathrm{a}$ \\
\hline 150 L.ha $^{-1}$ & $2.648,43 \mathrm{~b}$ & $1.073,48 \mathrm{~b}$ & $189,80 \mathrm{~b}$ \\
\hline $\begin{array}{l}\text { Method of } \\
\text { Application }\end{array}$ & & & \\
\hline With bar & $2.651,09 \mathrm{~b}$ & $1.133,94 \mathrm{~b}$ & $232,32 \mathrm{~b}$ \\
\hline No bar & $2.662,18 \mathrm{a}$ & $1.207,08 \mathrm{a}$ & $302,25 \mathrm{a}$ \\
\hline
\end{tabular}

Table 1: AUDPC averages for the three thirds in relation to volume and method of application. Ponta Grossa (PR), 2016.

The averages of treatments that present at least one common letter do not differ from each other, by the Tukey test at $5 \%$ probability.
As there was interaction between the factors in the middle third of the plants, the Tukey's test was applied (Table 2), where the treatment with 100 L.ha $^{-1}$ volume and without auxiliary bar was the least efficient in the control of rust in relation to the use of the bar, and for the volume 150 L.ha $^{-1}$ there was no significant difference associated with the use or not of the bar. The use of the auxiliary bar presented a significantly higher control when associated with the 150 L.ha $^{-1}$ volume. The method without auxiliary bar, also showed that when associated with the volume of 150 L.ha-1 $^{-1}$ was superior in the control of rust in relation to the volume of $100{\mathrm{~L} . h a^{-1}}^{-}$.

The averages followed by the same lowercase letter do not differ statistically from one another in columns and the averages followed by the same capital letter do not differ statistically from each other in the lines by the Tukey test at the $5 \%$ probability level.

\begin{tabular}{|l|c|c|}
\hline \multirow{2}{*}{ Volume of Application } & \multicolumn{2}{|c|}{ Method of Application } \\
\cline { 2 - 3 } & With bar & No bar \\
\hline 100 L.ha $^{-1}$ & $1.206,52 \mathrm{aB}$ & $1.328,57 \mathrm{aA}$ \\
\hline 150 L.ha $^{-1}$ & $1.061,37 \mathrm{bA}$ & $1.085,59 \mathrm{bA}$ \\
\hline
\end{tabular}

Table 2: AUDPC averages for interaction between volume and method of application in the middle third of soybean plants. Ponta Grossa (PR), 2016.

\section{Severity}

Applying the Tukey test (Table 3), the results showed that in the three evaluation dates there were lower values of severity in the condition of the highest volume of fungicide applied (150 L.ha-1).

The averages of treatments that present at least one common letter do not differ from each other, by the Tukey test at $5 \%$ probability.

The means of the main treatments in relation to the control were statistically different by the Dunnett test with $5 \%$ of significance.

\begin{tabular}{|l|llc|}
\hline Volume of Application & 57 DAS & 77 DAS & 93 DAS \\
\hline $100 \mathrm{~L} \mathrm{ha}^{-1}$ & $3,59 \mathrm{a}$ & $45,51 \mathrm{a}$ & $71,64 \mathrm{a}$ \\
\hline $150 \mathrm{~L} \mathrm{ha}^{-1}$ & $2,66 \mathrm{~b}$ & $39,93 \mathrm{~b}$ & $69,79 \mathrm{~b}$ \\
\hline Method of Application & & & \\
\hline With bar & $2,92 \mathrm{a}$ & $41,68 \mathrm{~b}$ & $70,32 \mathrm{~b}$ \\
\hline No bar & $3,34 \mathrm{a}$ & $43,76 \mathrm{a}$ & $71,12 \mathrm{a}$ \\
\hline
\end{tabular}

Table 3: Severity averages for the evaluation dates in relation to the volume and method of application. Ponta Grossa (PR), 2016. 
Thousand grain mass and Productivity

In relation to the thousand grain mass and productivity, the applied treatments were significantly superior in relation to the control.

In the Table 4, it can be observed that for both thousand grain mass and grain yield, the volume of 100 L.ha- 1 presented no significant difference with and without the use of the auxiliary bar, however, with the volume of $150 \mathrm{~L}$. ha ${ }^{1}$ associated with the auxiliary bar, was significantly higher than the treatment without the bar.

The averages followed by the same lowercase letter do not differ statistically from one another in columns and the averages followed by the same capital letter do not differ statistically from each other in the lines by the Tukey test at the $5 \%$ probability level.

\begin{tabular}{|c|c|c|c|c|}
\hline \multirow{3}{*}{$\begin{array}{l}\text { Volume of } \\
\text { application }\end{array}$} & \multicolumn{2}{|c|}{$\begin{array}{c}\text { Thousand grain } \\
\text { mass (g) }\end{array}$} & \multicolumn{2}{|c|}{ Productivity (kg.ha ${ }^{-1}$ ) } \\
\hline & \multicolumn{4}{|c|}{ Method of Application } \\
\hline & With bar & No bar & With bar & No bar \\
\hline 100L.ha ${ }^{-1}$ & $90,75 \mathrm{bA}$ & $98,02 \mathrm{aA}$ & $2.171,55 \mathrm{bA}$ & $2.219,78 \mathrm{aA}$ \\
\hline 150L.ha-1 & 106,83 aA & $92,12 \mathrm{aB}$ & $2.745,94 \mathrm{aA}$ & $2.233,89 \mathrm{aB}$ \\
\hline
\end{tabular}

Table 4: Averages of thousand grain mass ( $\mathrm{g}$ ) and productivity $\left(\mathrm{kg} \cdot \mathrm{ha}^{-1}\right.$ ) for interaction between the factors volume and method of application. Ponta Grossa (PR), 2016.

\section{Conclusion}

The control of Asian rust in the soybean crop evaluated by the AUDPC and severity was more efficient when applied in isolation way the fungicide volume of 150 L.ha $^{-1}$ and the method with the use of the auxiliary bar in the lower and upper thirds. And, in an associated way, the same treatments were better in the middle third of the plants.

In the yield of the crop evaluated by the thousand grain mass (g) and productivity ( $\left.\mathrm{kg} \cdot \mathrm{ha}^{-1}\right)$, the best results were obtained with a volume of 150 L.ha $^{1}$ associated to the use of the auxiliary bar.

\section{Bibliography}

1. Godoy CV., et al. "Diagrammatic scale for evaluation of the severity of soybean rust". Brazilian Phytopathology 31 (2006): 65.

2. Campbell CL and Madden LV. "Introduction to plant disease epidemiology". New York NY. Wiley, (1990): 532.
3. Fürstenberger ALF and Canteri MG. "AACPD - Software for calculating the area under the disease progress curve in the environment". Windows. (1999).

4. SILVA., et al. "Principal Components Analysis in the Software Assistat-Statistical Attendance". In: world congress on computers in agriculture, 7, Reno-NV-USA: American Society of Agricultural and Biological Engineers (2009).

\section{Volume 3 Issue 8 August 2019}

(c) All rights are reserved by Priscila Paula Ribeiro. 